\title{
Obtención de jarabes glucosados a partir de cáscaras de plátano (Musa paradisiaca L.) mediante hidrólisis enzimática de celulasas
}

\author{
Obtaining glucosed syrups from husks of Banana (Musa \\ paradisiaca L.) by enzymatic hydrolysis of cellulases
}

iD Alicia Decheco Egúsquiza $\square$

Universidad Le Cordon Bleu - Lima, Perú.

\begin{tabular}{llll}
\hline Recibido: 12/04/2018 & Revisado: 21/04/2019 & Aceptado: 03/06/2019 & Publicado: 30/06/2019
\end{tabular}

\section{RESUMEN}

El objetivo fue determinar el efecto de la aplicación de la enzima Celulasa fúngica en las cáscaras de plátano de seda (Musa paradisiaca) para la obtención de jarabe glucosado. Se estudió la hidrólisis enzimática de las cáscaras de plátano de seda al $30 \%(\mathrm{p} / \mathrm{v})$ a una temperatura constante de $50{ }^{\circ} \mathrm{C}$.

Las variables independientes para controlar fueron la concentración de la enzima Celulasa fúngica $(0,5 \%, 1 \%$ y $1,5 \% \mathrm{p} / \mathrm{v})$ y el tiempo de hidrolisis $(18,24$ y 30 horas). Las variables dependientes fueron el porcentaje de azúcar reductor y el porcentaje de equivalente de dextrosa (D.E.) de las muestras hidrolizadas enzimáticamente.

El diseño experimental fue completamente al azar con modelo factorial 32. Se obtuvo jarabes glucosados a partir de cáscaras de plátano de seda por la hidrólisis enzimática de la Celulasa fúngica. Los mayores porcentajes de azúcar reductor y de equivalente de dextrosa se presentaron en la concentración de Celulasa al 1,5\% (p/v) durante un tiempo de hidrolisis de 30 horas con valores promedio de $15,5 \%$ de porcentaje de azúcar reductor y de $30,9 \%$ de porcentaje de equivalente de dextrosa.

En la hidrólisis enzimática con Celulasa fúngica al 1,5\% (p/v) y 30 horas se obtuvo un producto de mayor valor agregado, se definieron las condiciones de operación y las etapas del proceso que deberían ser adaptadas para la producción de jarabe glucosado a partir de cáscaras de plátano (Musa paradisiaca).

Palabras clave: Cáscara de plátano, Lignocelulosa, Celulasa, Jarabes glucosados.

\begin{abstract}
The objective was to determine the effect of the application of the fungal cellulase enzyme on the silk banana peels (Musa paradisiaca) to obtain glucosed syrup. The enzymatic hydrolysis of banana shells at $30 \%(\mathrm{~W} / \mathrm{v})$ was studied at a constant temperature of $50{ }^{\circ} \mathrm{C}$. The independent variables to be controlled were the concentration of the fungal cellulase enzyme $(0.5 \%, 1 \%$ and $1.5 \% \mathrm{w} / \mathrm{v}$ ) and the hydrolysis time (18, 24 and 30 hours). The dependent variables were the percentage of Reducer Sugar and the percentage of Dextrose Equivalent (D.E.) of the enzymatically hydrolysed samples.
\end{abstract}


The experimental design was completely randomized with factorial model 32. Glucosed syrups were obtained from silk plantain hulls by the enzymatic hydrolysis of the fungal cellulase. The highest percentages of Reducer Sugar and Dextrose Equivalent were presented in the Cellulase Concentration at 1.5\% ( $/ \mathrm{v} / \mathrm{v})$ during a hydrolysis time of 30 hours with average values of $15.5 \%$ of reducing sugar percentage and $30.9 \%$ of percentage of Dextrose Equivalent.

In the enzymatic hydrolysis with fungal cellulase at 1.5\% (w/ v) and 30 hours a higher value-added product was obtained, the operating conditions and the process steps were defined that should be adapted for the production of glucosed syrup from of banana peels (Musa paradisiaca).

Keywords: Banana peel, Lignocellulose, Cellulase, Glucose syrups.

\section{INTRODUCCIÓN}

Los residuos sólidos, semisólidos o líquidos pueden ser insumo para generar productos, obtener bioenergéticos y para reducir el impacto ambiental que ocasionan (MejíasBrizuela et al., 2016).

Una opción atractiva es utilizar residuos de la agroindustria como insumo de bajo costo y obtener sustancias químicas refinadas (Gil, 2008).

Por ello, se buscan opciones enérgicas limpias y medioambientales sostenibles utilizando estos residuos (Conesa, 2017), de lo contrario serian un gran problema ambiental debido a su disposición final (Mejías- Brizuela et al., 2016).

Es fundamental aprovechar los residuos generados y utilizar la materia prima residual para crear productos nuevos, colaborando en buscar el equilibrio sostenible del planeta. (Hernández et al., 2015).

Estos residuos corresponden a biomasa lignocelulósica (Mejías et al., 2016), que son biodegradables, renovables y su utilización es una opción sostenible y amigable con el medio ambiente (Arellano, 2015).
Se debe considerar que todos los desechos de frutas pueden ser usados en otros procesos, inclusive como biocombustibles (Monsalve et al., 2006).

Las cáscaras de plátano son residuos sólidos que resultan al consumir directamente la fruta o al procesarlas para la obtención de mermeladas, chifles y conservas, y que ya no son útiles para el proceso que los generó, pero que pueden aprovecharse para obtener un producto con valor agregado económico, comercial y principalmente colaborar en reducir una fuente de contaminación del medio ambiente.

La cáscara está constituida principalmente por celulosa, hemicelulosa y lignina, las cuales la hacen no comestible para los humanos, pero potencialmente aprovechable para obtener otros productos de valor agregado (Swaroopa y Krishna, 2004).

Para procesar la biomasa lignocelulósica se requiere las siguientes etapas: a) reducción de tamaño, si es necesario b) pretratamiento, c) hidrolisis de celulosa y hemicelulosa. 
Estas etapas pueden llevarse a cabo mediante distintas configuraciones de proceso y dentro de cada una de ella existe múltiples alternativas (Merino y Cherry, 2007).

La celulosa es un polímero de D-glucosa unida por enlaces glucosídicos $\beta-1,4$ que se estructuran en largas cadenas lineales (microfibrillas) unidas por puentes de hidrógeno y fuerzas de van der Waals intramoleculares, formando una estructura cristalina resistente a la hidrólisis y regiones amorfas susceptibles a la degradación enzimática (Ovando y Waliszewski, 2005).

La hemicelulosa es un polímero complejo de heteropolisacáridos formado por pentosas (D-xilosa y L-arabinosa) y hexosas (D-glucosa, D-manosa y D-galactosa) que forman cadenas ramificadas y los ácidos 4- O-metilglucurónico, D-galacturónico y D-glucurónico, los azúcares están unidos por enlaces $\beta-1,4$ y ocasionalmente por enlaces $\beta-1,3$ (Pérez et al., 2002).

Las celulasas son una mezcla de tres enzimas que actúan simultáneamente en la hidrólisis de la celulosa: endoglucanasa, celobiohidrolasa y celobiasa ( $\beta-$ glucosidasa).

Las primeras dos enzimas actúan directamente en la celulosa. Los principales productos de reacción son la celobiosa y la glucosa; la celobiosa es entonces hidrolizada a glucosa por la celobiasa.

Las endoglucanasas y las celobiohidrolasas degradan a las celodextrinas solubles y a la celulosa amorfa); sin embargo, la celobiohidrolasa degrada a la celulosa cristalina de una manera más eficiente (Bohorquéz y Herrera, 2005).
Los jarabes de glucosa es uno de los productos de gran valor comercial que pueden sustituir a la sacarosa o azúcar de mesa, o pueden ser utilizados para la obtención de jarabes de fructosa.

Son soluciones concentradas y purificadas de sacáridos nutritivos obtenidos a partir de hidrolisis ácida o enzimática. (Madrid y Cenzano, 2001).

Por tal motivo, se pretende obtener jarabes glucosados a partir de una materia prima diferente a la convencional como es el maíz y utilizar en este caso la cáscara de plátano como única materia prima esencial del proceso y darle valor agregado a productos o subproductos que sería una opción para incrementar el nivel comercial de este insumo y disminuir los costos de la disposición de residuos y su efecto en el ambiente.

\section{MATERIALES Y MÉTODOS}

\section{Muestra}

Se trabajó con $10 \mathrm{~kg}$ de cáscaras de plátano de seda al $30 \%$ (p/v) seleccionados aleatoriamente, para evaluar la hidrólisis de sus componentes por el método de hidrólisis enzimática.

\section{Unidad experimental}

Estuvo conformada por cáscaras de plátano de seda con pretratamiento físico, químico y térmico que se obtuvo en condiciones de laboratorio para tener suficiente cantidad para las pruebas de hidrólisis enzimática.

\section{Procedimiento}

Los diagramas de flujo del proceso de hidrólisis enzimática aplicado a cáscaras de plátano de seda al $30 \%$ (p/v) para obtener el jarabe y las fotografías se muestran en la Figura 1 y 2 . 


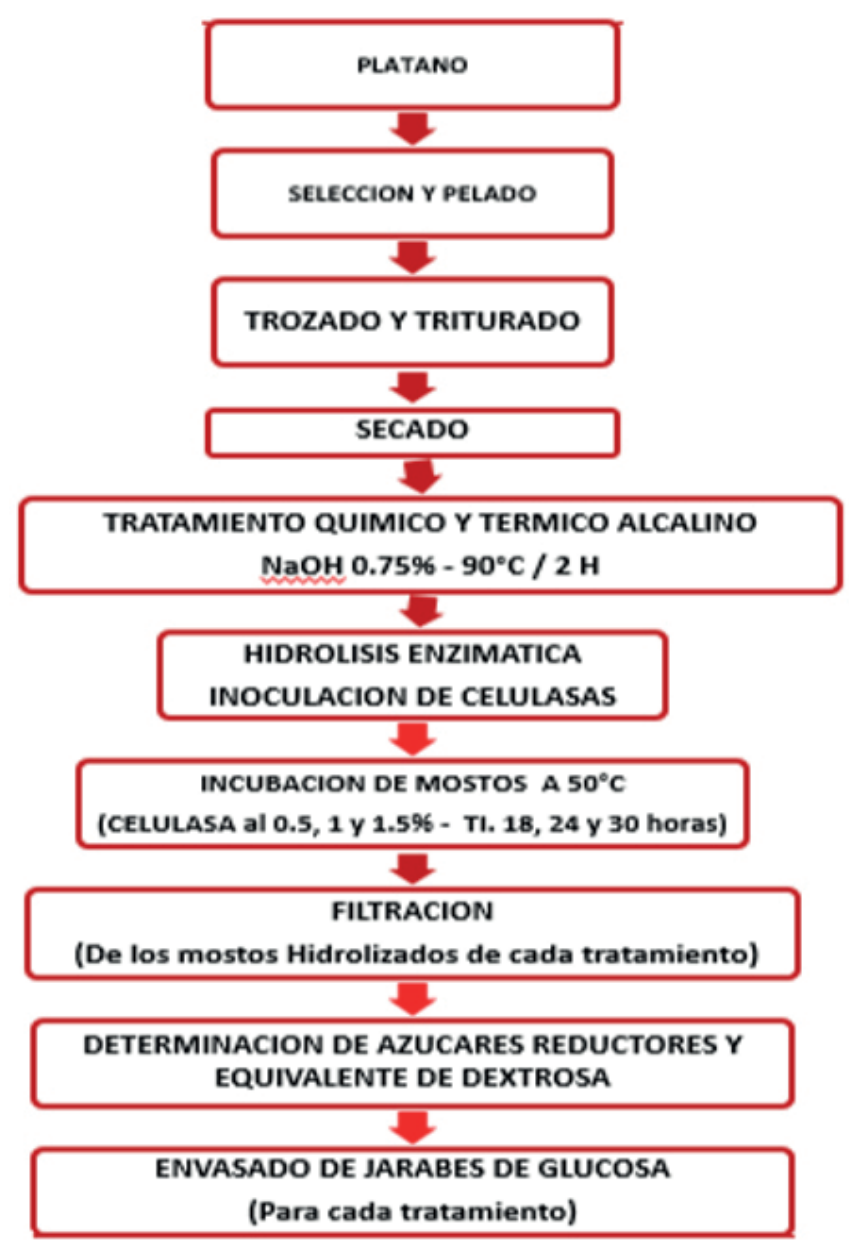

Figura 1. Diagrama del proceso de hidrólisis enzimática aplicado a las cáscaras de plátano

Etapa 1: Pre-tratamiento físico y químico de las cáscaras de plátano
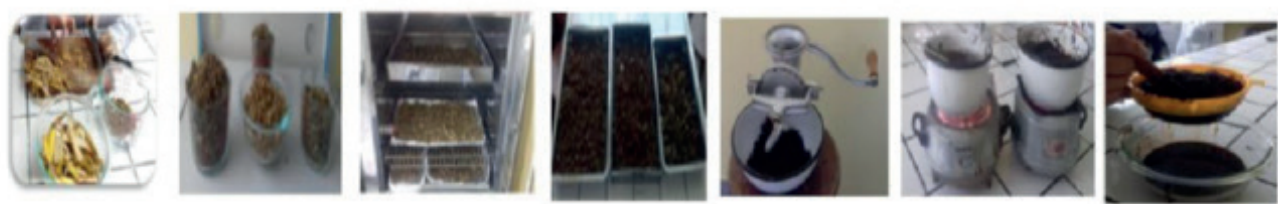

Etapa 2: Hidrolisis enzimática de Celulasa al 0,5\%, 1 \% y 1,5\% (p/v)
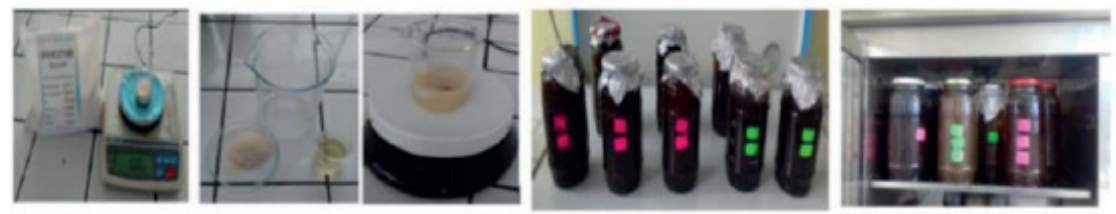

Rev. Investigaciones ULCB. Ene - jun. 6(1), 2019; ISSN: 2409 - 1537; 65 - 75. 
Etapa 3: Calidad del jarabe mediante evaluación de contenido de azúcares reductores
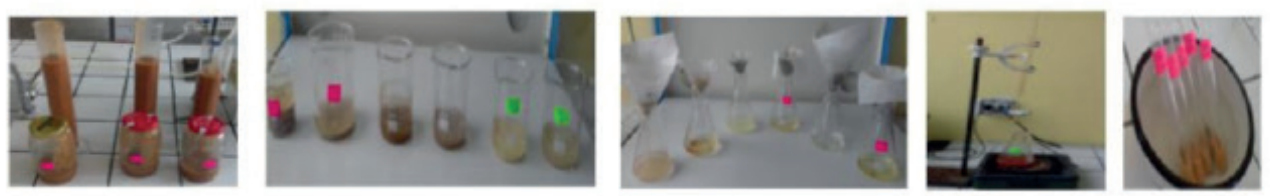

Figura 2. Fotografías del desarrollo del proceso de hidrólisis de cáscaras de plátano

Las variables independientes estudiadas fueron la concentración de la celulasa fúngica al $0,5 \%, 1 \%$ y $1,5 \%(p / v)$ y el tiempo de hidrolisis de 18, 24 y 30 horas. Las variables dependientes estudiadas fueron el contenido de azúcares reductores y equivalente de dextrosa (DE) de las muestras hidrolizadas enzimáticamente.

Prueba de determinación de porcentaje de azúcares reductores

Para la determinación cuantitativa del contenido de azúcares reductores se utilizó el método volumétrico de Eynon-Lane (INDECOPI NTP 203.002-1979 y INDECOPI NTP 208.102:2014).

Prueba de determinación de porcentaje de equivalente de dextrosa (ED).

La cuantificación de ED se realizó tomando como base los azúcares reductores y la cantidad en sustancia seca de la muestra de jarabe utilizada.

E.D. $=$ \% Azúcares reductores (base seca) $\times 100$ $\%$ Extracto seco (base seca)

Para obtener el porcentaje de extracto seco (\% ES), de 100 se restó el porcentaje de humedad (INDECOPI. NTP 209.264. 2001) del jarabe, es decir:
$\%$ ES $=100-\%$ humedad de la muestra de jarabe

\section{Análisis estadístico}

Los resultados obtenidos se analizaron con el programa estadístico SPSS, versión 20, empleándose el diseño factorial, $3 \times 2$ con 3 repeticiones, así como la prueba de análisis de varianza (ANVA) y prueba de Duncan, para determinar si hubo un efecto significativo $(p<0,05)$ en los diferentes tratamientos de concentración de enzima y tiempo de acción de esta sobre el índice de dextrosa (ED).

\section{RESULTADOS}

Se determinaron los valores de solidos solubles ('Brix), azúcares reductores (\%), equivalente de dextrosa (\%) cuyos resultados se ve en la Tabla 1.

En general, se pudo observar que los mayores porcentajes de azúcar reductor y de equivalente de dextrosa se presentaron en la concentración de celulasa al $1.5 \%$ $(\mathrm{p} / \mathrm{v})$ durante 30 horas de hidrolisis con valor promedio de $15.5 \%$ de porcentaje de azúcar reductor y de $30.9 \%$ de porcentaje de equivalente de dextrosa. 
Tabla 1. Relación entre la concentración de la enzima Celulasa y el tiempo de hidrólisis con el \% azúcares reductores y el \% equivalente de dextrosa de los jarabes

\begin{tabular}{|c|c|c|c|c|c|}
\hline$\%$ Celulasa & $\begin{array}{l}\text { Tiempo } \\
\text { (horas) }\end{array}$ & $\begin{array}{l}\text { \% Azúcar } \\
\text { reductor }\end{array}$ & $\begin{array}{l}\text { \% Azúcar } \\
\text { reductor } \\
\text { promedio }\end{array}$ & $\begin{array}{c}\% \\
\text { Equivalente } \\
\text { dextrosa }\end{array}$ & $\begin{array}{c}\text { \% Equivalente } \\
\text { dextrosa } \\
\text { promedio }\end{array}$ \\
\hline 0.5 & 18 & 2.8 & 3.1 & 7.0 & 7.2 \\
\hline 0.5 & 18 & 3.1 & 3.1 & 7.2 & 7.2 \\
\hline 0.5 & 18 & 3.3 & 3.1 & 7.5 & 7.2 \\
\hline 0.5 & 24 & 6.5 & 6.9 & 13.8 & 14.9 \\
\hline 0.5 & 24 & 7.0 & 6.9 & 15.3 & 14.9 \\
\hline 0.5 & 24 & 7.2 & 6.9 & 15.5 & 14.9 \\
\hline 0.5 & 30 & 7.6 & 7.6 & 17.4 & 17.5 \\
\hline 0.5 & 30 & 7.7 & 7.6 & 17.8 & 17.5 \\
\hline 0.5 & 30 & 7.5 & 7.6 & 17.2 & 17.5 \\
\hline 1 & 18 & 8.1 & 8.3 & 17.6 & 18.2 \\
\hline 1 & 18 & 8.3 & 8.3 & 18.2 & 18.2 \\
\hline 1 & 18 & 8.5 & 8.3 & 18.9 & 18.2 \\
\hline 1 & 24 & 11.0 & 11.0 & 20.3 & 20.3 \\
\hline 1 & 24 & 10.6 & 11.0 & 19.5 & 20.3 \\
\hline 1 & 24 & 11.3 & 11.0 & 21.1 & 20.3 \\
\hline 1 & 30 & 12.0 & 11.5 & 23.2 & 22.5 \\
\hline 1 & 30 & 11.7 & 11.5 & 22.6 & 22.5 \\
\hline 1 & 30 & 10.9 & 11.5 & 21.7 & 22.5 \\
\hline 1.5 & 18 & 9.2 & 9.4 & 19.1 & 19.5 \\
\hline 1.5 & 18 & 9.7 & 9.4 & 19.9 & 19.5 \\
\hline 1.5 & 18 & 9.4 & 9.4 & 19.5 & 19.5 \\
\hline 1.5 & 24 & 12.8 & 13.1 & 25.6 & 25.8 \\
\hline 1.5 & 24 & 13.4 & 13.1 & 26.0 & 25.8 \\
\hline 1.5 & 24 & 13.2 & 13.1 & 25.9 & 25.8 \\
\hline 1.5 & 30 & 15.7 & 15.5 & 30.6 & 30.9 \\
\hline 1.5 & 30 & 14.9 & 15.5 & 29.5 & 30.9 \\
\hline 1.5 & 30 & 15.8 & 15.5 & 32.6 & 30.9 \\
\hline
\end{tabular}

Conforme disminuía la viscosidad de las soluciones, iba aumentando en forma creciente los grados Brix y formándose azúcares reductores en diferentes niveles de acuerdo con la concentración de la enzima: 0,5, 1 y 1,5\% (p/v) y los tiempos de hidrolisis de 18, 24 y 30 horas.

Al finalizar los tiempos de incubación para la hidrólisis enzimática con la celulasa al 0,5; 1 y
1,5\% (p/v) el líquido filtrado tenía una tonalidad marrón amarillenta.

La concentración enzimática de la celulasa de mejor rendimiento de la reacción de hidrólisis fue del $1.5 \%$ durante una incubación de 30 horas puesto que se obtuvieron hidrolizados con mayores grados Brix y porcentajes de azúcares reductores (Figura 3 y 4). 


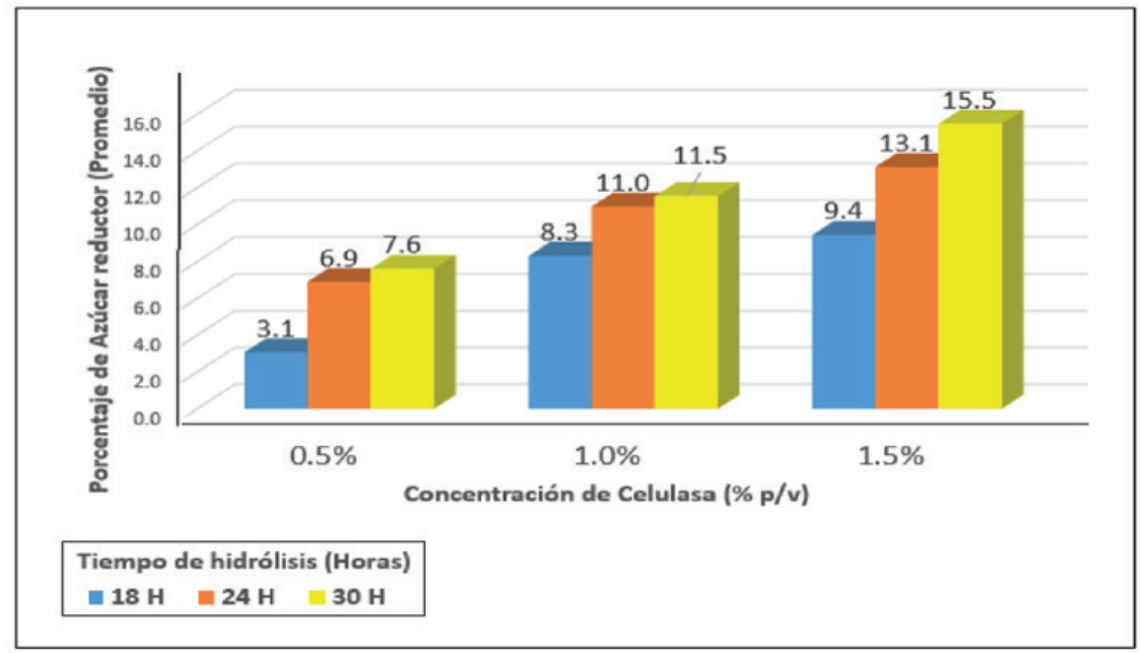

Figura 3. Relación entre la concentración de la enzima celulasa y el tiempo de hidrólisis con el \% azúcares reductores (AR)

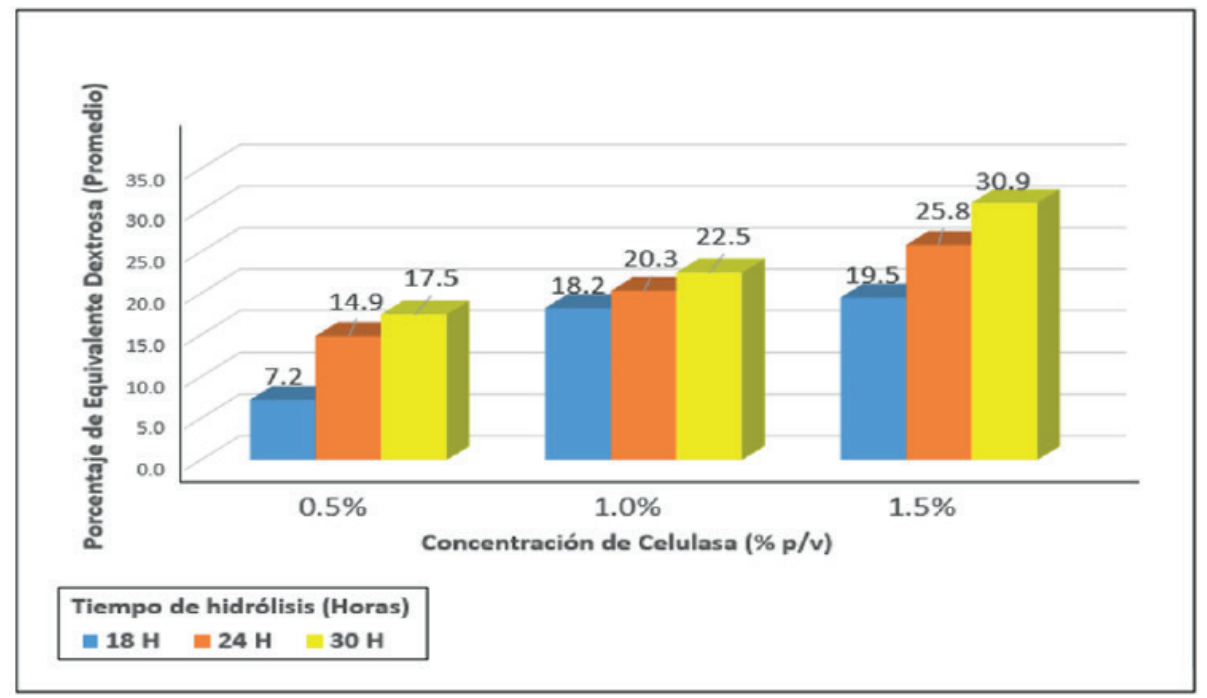

Figura 4. Relación entre la concentración de la enzima celulasa y el tiempo de hidrólisis con el porcentaje de equivalente de dextrosa

CLos análisis estadísticos demostraron que existieron diferencias significativas entre la concentración de celulasa utilizada y los tiem- pos de hidrolisis versus el porcentaje de azúcar reductor y el \% de equivalente de dextrosa (Tabla 2). 
Tabla 2. Análisis de varianza de la relación entre la concentración de celulasa y el tiempo de hidrólisis con el porcentaje de azúcar reductor y el porcentaje de equivalente de dextrosa

\begin{tabular}{lcccccc}
\hline $\begin{array}{c}\text { Origen de las } \\
\text { variaciones }\end{array}$ & $\begin{array}{c}\text { Sumade } \\
\text { cuadrados }\end{array}$ & $\begin{array}{c}\text { Grados de } \\
\text { libertad }\end{array}$ & $\begin{array}{c}\text { Promedio } \\
\text { de los } \\
\text { cuadrados }\end{array}$ & F & Probabilidad & $\begin{array}{c}\text { Valor } \\
\text { crítico } \\
\text { para F }\end{array}$ \\
\hline $\begin{array}{l}\text { \% Celulasa }(\mathrm{p} / \mathrm{v}) \\
\text { Tiempo de }\end{array}$ & 71.8 & 2.00 & 35.91 & 64.53 & $0.00^{*}$ & 6.94 \\
$\begin{array}{l}\text { hidrólisis } \\
\text { Error }\end{array}$ & 34.2 & 2.00 & 17.08 & 30.69 & $0.00^{*}$ & 6.94 \\
Total & 2.2 & 4.00 & 0.56 & & & \\
\hline
\end{tabular}

AV del \% equivalente de dextrosa

\begin{tabular}{lcccccc}
\hline $\begin{array}{l}\text { Origen de las } \\
\text { variaciones }\end{array}$ & $\begin{array}{c}\text { Sumade } \\
\text { cuadrados }\end{array}$ & $\begin{array}{c}\text { Grados de } \\
\text { libertad }\end{array}$ & $\begin{array}{c}\text { Promedio } \\
\text { de los } \\
\text { cuadrados }\end{array}$ & $\boldsymbol{F}$ & Probabilidad & $\begin{array}{c}\text { Valor } \\
\text { crítico } \\
\text { para F }\end{array}$ \\
\hline $\begin{array}{l}\text { \% Celulasa }(\mathrm{p} / \mathrm{v}) \\
\text { Tiempo de }\end{array}$ & 226.3 & 2.00 & 113.13 & 26.59 & $0.00^{*}$ & 6.94 \\
hidrólisis & 113.9 & 2.00 & 56.96 & 13.38 & $0.02^{*}$ & 6.94 \\
Error & 17.0 & 4.00 & 4.26 & & & \\
Total & 357.2 & 8.00 & & & & \\
\hline
\end{tabular}

Criterio estadístico: 95\% de confianza

Se presentaron diferencias significativas $(*)$

\section{DISCUSIÓN}

Para el presente estudio se utilizó muestras de cáscara de plátano de seda al $30 \%(\mathrm{p} / \mathrm{v})$ y la enzima Gramozyme Celulasa fungal en diferentes concentraciones que provocó la hidrólisis del polisacárido celulosa de la cáscara a oligosacáridos de cadena corta que se evidenció por el aumento del porcentaje de azúcar reductor y el porcentaje de equivalente de dextrosa y la obtención de jarabes glucosados.

Al respecto, Krogh et al., (2004); Wen et al., (2005); Sehnem et al., (2006), proponen el uso de enzimas segregadas por hongos filamentosos para la hidrólisis enzimática de residuos lignocelulósicos como son: las celulasas, que engloban un conjunto de enzimas que hidrolizan la celulosa cristalina a pequeños oligosacáridos y posteriormente a glucosa; y las hemicelulasas, que hidrolizan la hemicelulosa a azúcares monoméricos.

Al respecto, Medina (2011), señaló que la hidrolisis enzimática ha cobrado mucha importancia ya que es un proceso poco agresivo para el material y para el medio en el que se trabaja y que el único requerimiento para una hidrolisis enzimática es ajustar las condiciones, como el pH y la temperatura para que el proceso enzimático se lleve a cabo adecuadamente. 
Los jarabes que se obtuvieron de hidrólisis enzimática de acuerdo a BeMiller y Whistle (2009) fueron del tipo I que consisten principalmente de segmentos de peso molecular alto y dextrinas lineales.

Esta categoría obtenida se explica porque la hidrólisis enzimática de la celulasa fue limitante ya que no tuvo valores altos de azúcares reductores y equivalentes de dextrosa como se esperaba, esto es por la poca eliminación de la lignina que limitaba la acción de la enzima celulasa.

Al respecto, Martín y Manzanares, (1994) informan que la celulosa está muy bien protegida para el ataque por agentes químicos y biológicos.

Las moléculas se encuentran sólo dentro de las microfibrillas y rodeadas de una matriz de otros materiales reactivos. Esto supone la existencia de sucesivas barreras protectoras que dificultan el acceso de agentes químicos y enzimas a las cadenas de celulosa.

Esto concuerda con Han et al., (2011) quienes mencionan que la conversión de biomasa lignocelulósica a otros productos es un proceso complejo debido a la estructura química de la pared celular de este material vegetal, por lo tanto, es necesario implementar un tratamiento previo el cual permita pasar de un complejo celulósico a azúcares fermentables que contengan principalmente glucosa.

Es importante continuar con estudios de evaluación de hidrolisis enzimática de la celulosa tomando en consideración diferentes factores que puedan regularla.

Los jarabes glucosados obtenidos, se pueden considerar aptos para su consumo adicionándolo en bebidas naturales, energéticas o vitamínicas, de diferente composición, ricos en oligosacáridos de cadenas lineales cortas o maltodextrinas que pueden ser utilizados en la industria por sus propiedades funcionales.

\section{CONCLUSIONES}

Existieron diferencias significativas entre los porcentajes de Celulasa utilizados y los tiempos de incubación versus el porcentaje de equivalente de dextrosa.

En la hidrólisis enzimática con Celulasa fúngica al $1.5 \%(\mathrm{p} / \mathrm{v})$ y 30 horas se obtuvo un producto de mayor valor agregado, se definieron las condiciones de operación y las etapas del proceso que deberían ser adaptadas para la producción de jarabe glucosado a partir de cáscaras de plátano de seda.

Una mayor fluidez se observó en los hidrolizados obtenidos a una concentración de la enzima Celulasa al 1,5\% y con un tiempo de incubación de 30 horas.

Los hidrolizados obtenidos en la hidrólisis enzimática fueron poco viscosos, marrón amarillento y con brillo moderado.

\section{REFERENCIAS BIBLIOGRÁFICAS}

Arellano Perales, C. (2015). Obtención de bioetanol a partir de materiales lignocelulósicos sometidos a hidrolisis enzimática. Tesis de Maestría en Ciencias en procesos biológicos. Universidad Veracruzana. Veracruz. México. Recuperado de:

file://C:/Users/USER/Downloads/Dialnet-Pr oduccionDeBioetanolAPartirDeSubproductos Agroindu-3628225.pdf

BeMiller, J., y Whistler, R. (2009). Starch Chemistry and Technology. USA. Food Science and Technology, International Series. Third Edition. 
Bohórquez, C., y Herrera, S. (2005). Determinación de las mejores condiciones de hidrólisis del banano verde de rechazo. Trabajo de Licenciatura. Universidad Nacional de Colombia. Medellín. Colombia.

Conesa, D. C. (2017). Desarrollos tecnológicos para la mejora y control del proceso de obtención de bioetanol a partir de residuos agroalimentarios. Tesis Doctoral. Universitat Politécnica de Valencia. Valencia (España). Doi: 10.4995/Thesis/10251/861446.

Gil-Horán, R. H., Domínguez-Espinosa, R. M., y Pacho-Carrillo J. D. (2008). Bioproducción de ácido láctico a partir de residuos de cáscara de naranja: Procesos de separación y purificación. Tecnol. Ciencia Ed. (IMIQ). 23(2), 79-90.

Han, M., Kim, Y., Kim, Youngran, Chung, B. y Choi, G. (2011). Bioethanol production from optimized pretreatment of cassava stem. Korean J. Chem. Eng., January, Vol. 28, No.1: 119-125.

Hernández N. G., Santamaría O. A., y Rubio T. M. (2015). Aprovechamiento concientizado de los residuos como materia prima para el diseño de nuevos productos. Revista Iberoamericana de Ciencias, 2(5), 71-81. Recuperado de URI: http://hdl.handle. net/20.500.11799/58281.

INDECOPI. NTP 203.002-1979. Determinación del contenido de Azúcares reductores. Método de Eynon-Lane. 1979.

INDECOPI. NTP 209.264. 2001. Determinación de Humedad. Método gravimétrico. $1^{\text {a }}$ Edición. 2001.

INDECOPI. NTP 208.102:2014 CONFITERÍA. Determinación de Azúcares reductores y sacarosa. 1ª Edición. 2014.
Krogh, K.B., Morkeberg, A., Jorgensen, H., Frisvad, J.C., y Olsson, L. (2004). Screening genus Penicillium for producers of cellulolytic and xylanolytic enzymes. Appl Biochem Biotechnol. 114, 389-401.

Madrid, A. y Cenzano, J. (2001). Nuevo Manual de Industrias Alimentarias. España. Editorial Mundi-Prensa Libros. S.A.

Martín, C. y Manzanares, P. (1994). Biomasa lignocelulósica. Polímeros constitutivos. Procesos biológicos de degradación de lignina. Centro de Investigaciones Energéticas, Medioambientales y Tecnológicas (CIEMAT 754 - ISSN 0214-087X). Madrid, España.

Medina-Morales M., Lara-Fernández, L., Aguilar, C. N. y De La Garza-Toledo, H. (2011). Aprovechamiento de materiales lignocelulósicos para la producción de etanol como carburante. Revista Científica de la Universidad Autónoma de Coahuila. 3(6), 35- 41.

Mejías-Brizuela, N., Orozco-Guillen, E., y GalánHernández, N. (2016). Aprovechamiento de los residuos agroindustriales y su contribución al desarrollo sostenible de México. Revista de Ciencias Ambientales y Recursos Naturales, 2, (6): 27-41. Recuperado de https://www. researhgate.net/publication/323959087_ Aprovechamiento_dee_los_residuos_agro industriales_y_su_contribucion_al_desarrollo_ sostenible_de_Mexico

Merino, S., y Cherry, J. (2007). Progress and Challenges in Enzyme Development for Biomass Utilization. Adv Biochem Engin/ Biotechnol. 108: 95-120. June.

Monsalve G. J., Medina de Pérez, V., y Ruiz Colorado, A. (2006). Producción de etanol a partir de la cáscara de banano y almidón de yuca. Dyna. Año 73. 150, 21-27. Medellín, Noviembre ISSN 0012-7353. Recuperado 
de $\quad$ https://www.redalyc.org/articulo. oa?id=49615002.

Ovando Chacón, S.L., y Waliszewski, K.N. (2005). Preparativos de celulasas comerciales y aplicaciones en procesos extractivos. Universidad y Ciencia. 21, 111-120.

Pérez J., Muñoz-Dorado A., De la Rubia, T. y Martínez, E. (2002). Biodegradation and biological treatments of cellulose, hemicellulose and lignin: an overview. Int. Microbiol. 5, 53-63.

Sehnem, N.T., Bittencourt, L.R., Camassola, M., y Dillon, A. J. P. (2006). Cellulase production by Penicillium echinulatum on lactose. Appl Microbiol Biotechnol. 72,163-167.

Swaroopa Rani, R., y Krishna, N. (2004). Ensilage of pineapple processing waste for methane generation. Science Direct, 523528.

Wen, Z., Liao, W., y Chen, S. (2005). Production of cellulase/ $\beta$-glucosidase by the mixed fungi culture Trichoderma reesei and Aspergillus phoenicis on dairy manure. Process Biochem. 40, 3087-3094. 